\title{
EDUCAÇÃO FÍSICA CRÍTICA EM PERSPECTIVA DEMOCRÁTICA E REPUBLICANA
}

\author{
CRITICAL PHYSICAL EDUCATION IN A DEMOCRATIC AND REPUBLIC \\ PERSPECTIVE
}

EDUCACIÓN FÍSICA CRÍTICA EN PERSPECTIVA DEMOCRÁTICA Y

REPUBLICANA

Paulo Evaldo Fensterseifer*, Fernando Jaime González*, Sidinei Pithan da Silva*

\begin{abstract}
Palavras chave:
Teoria Crítica.

Democracia.

República.

Educação Física.

Resumo: 0 presente estudo consiste em um ensaio teórico que analisa limites e potencialidades dos discursos educacionais críticos que aspiram à mudança social. Busca, sobretudo, pensar um projeto de Educação Física (EF) comprometido com questões democráticas e republicanas. Para tanto, aponta, a partir da filosofia política de Hannah Arendt a necessidade de distinguir educação e política, reconhecendo o valor do conhecimento e da especificidade da EF. Condição que não impede e limita 0 valor dos aportes teóricos e críticos que permitem interpretar as relações entre educação e sociedade em cada momento histórico, o que sugere um aspecto complementar entre as tradições hermenêuticas, crítico-dialéticas e pós-estruturalistas para pensar o fenômeno da EF e sua relação com o tema da república, da educação e da democracia.
\end{abstract}

Keywords:

Critical Theory.

Democracy.

Republic.

Physical Education.

Palabras clave: Teoría Crítica. Democracia. República. Educación Física.

Abstract: The present study consists of a theoretical essay that analyzes the limits and potentialities of critical educational discourses that aspire to social change. It looks for, mainly, to think about a project of Physical Education (PE) committed to democratic and republican issues. To do so, it points out, from the political philosophy of Hannah Arendt the need to distinguish education and politics, recognizing the value of knowledge and the specificity of PE. This condition does not prevent and limit the value of the theoretical and critical contributions that allow us to interpret the relations between education and society in each historical moment, suggesting a complementary aspect between the hermeneutic, critical-dialectical and poststructuralist traditions to think about the phenomena of PE and its relationship to the theme of the republic, education and democracy.

Resumen: Este estudio consiste en un ensayo teórico que analiza los límites y las potencialidades de los discursos educativos críticos que aspiran al cambio social. Busca, sobre todo, pensar en un proyecto de Educación Física (EF) comprometido con temas democráticos y republicanos. Para este fin, señala, en base a la filosofía política de Hannah Arendt, la necesidad de distinguir educación y política, reconociendo el valor del conocimiento y la especificidad de la EF. Una condición que no impide y limita el valor de las contribuciones teóricas y críticas que permiten la interpretación de las relaciones entre educación y sociedad en cada momento histórico, sugiriendo un aspecto complementario entre las tradiciones hermenéutica, crítico-dialécticas y post-estructuralistas para reflexionar sobre el fenómeno de la EF y su relación con el tema de la república, la educación y la democracia.
*UNIJUÍ, ljuí, RS, Brasil. E-mail: sidinei.pithan@unijui.edu.br; fenster@unijui.edu.br; fjg@unijui.edu.br

Recebido em: 29-03-2019 Aprovado em: 18-09-2019 Publicado em: 16-11-2019

DOI: https://doi.org/10.22456/1982-8918.95771 (c) (1) (8) Licence 


\section{INTRODUÇÃOO}

O presente artigo é um esforço empreendido no enfrentamento das seguintes questões: a educação pode mudar a sociedade? A educação pode ser crítica? A Educação Física (EF) pode ser compreendida e desenvolvida em uma perspectiva crítica em sentido democrático e republicano? Que perspectiva de crítica julgamos ainda possível e necessária? Iniciaremos por tematizar os vínculos da educação com a tradição crítica, indicando os riscos da politização empreendida no pensamento pedagógico que, em nosso entender, lidou mal com as complexas relações entre educação e política. Em um segundo momento, encetamos um esforço no sentido de analisar as condições de possibilidade do discurso educacional crítico no âmbito da mudança social. Importa retomar os aspectos da noção de crítica produzidas ao longo da modernidade, e mesmo as emergentes na contemporaneidade, a fim de pensar os vínculos entre educação e sociedade. Por último, evidenciaremos nosso entendimento acerca do que seria uma "EF crítica", tendo em vista as questões do republicanismo e da democracia.

\section{PODE A EDUCAÇÃO SER CRÍTICA?}

A decisão de "educar a todos" em um espaço formal, subsidiado por este "todos", é uma decisão política que tem seu momento inaugural nas sociedades modernas que promoveram uma ruptura com as tradições aristocráticas do Antigo Regime. Esta deliberação está umbilicalmente afinada com os regimes políticos que se instauraram, ou seja, as modernas repúblicas democráticas. Elas colocaram-se como herdeiras do legado do espírito das luzes, apostando alto no poder libertador do conhecimento, logo, nas instituições responsáveis por veicular estes conhecimentos. Conforme Todorov, as luzes promoveram "o elogio do conhecimento que liberta os seres humanos das tutelas exteriores opressoras", mas, acrescenta, "ele não consiste em dizer que, estando tudo determinado e portanto passível de conhecimento, os humanos aprenderão a controlar integralmente o mundo e a moldá-lo segundo seus desejos" (TODOROV, 2008, p. 27-28). E prossegue 0 autor,

Se quisermos hoje encontrar um apoio no pensamento das Luzes para enfrentar nossas dificuldades presentes, não podemos acolher todas as propostas formuladas no século XVIII - não somente porque o mundo mudou, mas também porque esse pensamento é múltiplo, não uno. É antes de tudo uma refundação das Luzes que precisamos: preservar a herança do passado, mas submetendo-o a um exame crítico, confrontando-o lucidamente com suas consequências desejáveis e indesejáveis. Fazendo isso, não arriscamos trair as Luzes; ao contrário: a verdade é que as criticando, continuamos fiéis a elas, e colocamos em prática seu ensinamento (TODOROV, 2008, p. 28-29).

De nossa parte, tomamos este ideário, nas suas promessas mais generosas, como horizonte do qual abstraímos os critérios para julgar/criticar suas manifestações empíricas no tempo e no espaço. Entre estas configurações que assumem caráter institucional, está a escola. Então, a posição que assumimos acerca do "nascimento" da educação escolar nas sociedades modernas é balizadora das posições críticas posteriores.

O marxismo, como herdeiro desta tradição crítica, carrega não só diferenças marcantes com outras posições teóricas, mas controvérsias em seu próprio interior. Por exemplo, quando ele identifica as sociedades modernas como sociedades burguesas, por decorrência suas instituições, entre elas a escola, não deriva automaticamente disso sua negação. Uma 
parte desta corrente, condena, de forma geral, o Estado Burguês, e, por conseguinte, suas instituições, entre elas a "escola burguesa".

Outra posição, entendemos mais fiel ao movimento dialético, reconhece no conjunto desta sociedade um avanço enorme em relação ao Antigo Regime. Sua crítica não aventa a liquidação das referidas instituições, porém as critica por não cumprirem suas promessas. Promessas que, é importante lembrar, foram forjadas com o escopo da universalidade condição de unir burgueses e proletários na mesma trincheira - mas, uma vez instituídas, não construíram as condições para lograr seu prometido intento: garantir educação escolar (de qualidade) para todos.

Esta limitação fez com que, para usar uma expressão de Michel Young (2007), o "conhecimento poderoso", resultante dos avanços científicos nas diferentes áreas, fosse apropriado exclusivamente pelos "poderosos" (daí o designativo "conhecimento dos poderosos"). A crítica a este fenômeno também não seguiu caminho linear. Alguns criticam o "pacote", logo, negando a totalidade ali envolvida (o conhecimento e aqueles que dele se apropriam para preservar a opressão). Outros separam as coisas, reconhecendo que o conhecimento, contingencialmente na mão dos poderosos, não deve ser desprezado, mas apropriado por aqueles que a ele não tem acesso, empoderando-os.

A crítica deve ser então endereçada a tudo àquilo que impede a escola de cumprir seu papel; ensinar a todos o "conhecimento poderoso". Entendemos nesse esforço crítico a condenação de tudo àquilo que tenta "domar a escola" (MASSCHELEIN; SIMONS, 2013) desvinculando-a do seu fim.

É possível reconhecer como importante contribuição das teorias críticas na(da) educação a superação das crenças no "tecnicismo" e no "psicologismo", chamando a atenção para as determinações de natureza política que conformam a educação em uma determinada sociedade. Com esse ganho porém, vem um risco: "o politicismo", expresso no mantra: tudo é política. Acerca disso afirma Brayner (1995, p. 85) que:

Parece-me uma franca banalidade a afirmação de que "educar é um ato político". É evidente que ele o é: como ato civilizatório, que exprime interesses sociais, que prolonga ou nega heranças culturais, que repercute na vida cotidiana, que impõe saberes práticos, que institucionaliza visões de mundo, que normatiza a vida. O pensamento liberal, através da ainda recente herança iluminista, já o sabia. E advogava ainda por cima que a entrada na vida propriamente civil, política, não poderia prescindir da educação. (Grifos no original)

A afirmação de Paulo Freire acima grafada apontava, segundo Brayner, para uma "teleologia libertadora da educação", por um lado, e por outro seu potencial "alienante". Enfim, um "ato político". Na esteira desta "revelação" o pensamento pedagógico de matriz marxista, no entendimento de Brayner, vai apontar para a necessidade de "educar para formar agentes de transformação, para investir consciências ainda não politizadas dos instrumentos da 'libertação"'. E, conclui o autor, "A imaginação radical logo promoveu a educação como simples epifenômeno da luta de classes" (1995, p. 85).

Como já destacamos, certamente se tornou um ganho o reconhecimento de que a educação possui uma relação evidente com o universo político, porém não há uma relação linear disso com o que acontece no cotidiano escolar. Assim, as deliberações, ou simples tomadas de posição no universo político, necessitam da mediação pedagógica, e esta, se 
não quisermos estabelecer uma relação instrumental que reduza os educadores a meros "aplicadores", também tem suas vicissitudes. Logo, se não quisermos incorrer no "politicismo", temos que reconhecer à especificidade dos universos aí envolvidos.

As dificuldades em produzir vínculos efetivos entre as intencionalidades generosas do discurso crítico e a efetiva qualificação dos processos pedagógicos, vai produzindo um desgaste no próprio discurso, algo que permitiu observações irônicas, como as de Guiomar Namo de Mello (apud BRAYNER, 1995, p. 88): "No Brasil, tornou-se um ato revolucionário afirmar que cabe à escola ensinar. E ensinar bem! Não é seu papel formar militantes políticos, nem determinar o destino social, ideológico ou o projeto político de quem quer que seja".

O que podemos perceber é que tem sido tarefa fácil reconhecer o vínculo entre política e educação sem afirmar a indiferenciação de ambas. Esta indiferenciação é que levou a crítica que nega a sociedade burguesa a negar a "escola burguesa", tarefa de uma "educação revolucionária". Brayner lembra que "[...] o próprio Saviani já reconhecia que aqueles que denunciam a escola e a educação 'burguesas', são aqueles que passaram por suas bancas e que, portanto, adquiriram a aparelhagem necessária para o devido recuo crítico" (1995, p. 89).

A politização exagerada da educação alimenta "[...] a crença de que uma vez 'conscientes' (quer dizer 'politizados') através de uma educação adequada a tais fins, os sujeitos tenderiam naturalmente para ações transformativas estabelecendo uma identidade apriorística que deposita na consciência uma fé ingênua" (BRAYNER, 1995, p. 89). Esta crença sustenta, em nosso entender, os vínculos lineares entre educação e cidadania, "esquecendo" que o exercício da cidadania está no âmbito da ação e este não pode ser antecipado por processos formativos de modo mecânico. À formação caberia fornecer a base (critérios) sem a qual o exercício "crítico" da cidadania resultaria nulo ou empobrecido.

Podemos afirmar que ninguém é crítico por antecipação, assim como ninguém é ético por antecipação ao contexto da ação, logo, a escola não forma cidadãos. Não obstante, fornece elementos importantes para a crítica, para a reflexão ética e para as demandas da cidadania, ainda que sem nenhuma garantia de seu uso efetivo. Entendemos que esta é a contribuição da educação para o pensamento crítico, cabendo a cada disciplina, incluída a EF, elencar àqueles conhecimentos que podem empoderar as novas gerações para estabelecerem uma inserção reflexiva com o mundo que lhes coube viver. Este esforço deve ser prenunciado nos próprios processos educativos e este nos parece que tem sido uma das dificuldades do processo renovador (crítico) da EF.

Enfim, não basta a incorporação de um novo vocabulário ("crítico") que funciona como "verniz" para práticas que rotineiramente teimam em persistir. Este parece o recado endereçado desde a crítica de Brayner (1995), amparado em Hannah Arendt, à Paulo Freire e ao discurso crítico em geral. $O$ enfoque republicano de Brayner parece colocar contra a parede a ideia que advém da teoria crítica de origem marxiana, a qual pressupõe que o lugar da educação é o de transformar a sociedade. Para Arendt (2013), a educação é uma instância conservadora do mundo, pois lida com o conhecimento acerca de como o mundo é. A mudança do mundo incumbe nesta perspectiva hermenêutica de Arendt, aqui assumida por Brayner, à esfera da política.

Esta inflexão inicial acerca do pensamento republicano e liberal, nos desafia a buscar um contraponto no discurso crítico social, o que nos leva a pensar que enquanto o primeiro aponta para o valor da escola e da educação enquanto uma forma de conservação das tradições, e 
por isso de socialização de um bem comum, e construção de uma civilização, o segundo nos mostra o caráter inconcluso e contraditório da vida social, e portanto, da democracia no curso da vida Ocidental, o que torna o lugar da crítica, umbilicalmente ligado à ideia de educação e, mesmo de política.

\section{PODE A EDUCAÇÃO MUDAR A SOCIEDADE?}

Em um de seus últimos livros, o teórico norte-americano, Michael Apple (2017), se defronta com a pergunta acerca da relação entre educação e sociedade: a educação pode mudar a sociedade? Está em jogo para ele, um lugar e um papel dos educadores em sua responsabilidade pelo mundo. Sobretudo, a questão ética, ou mesmo o apelo moral, funciona como um imperativo, que desafia os teóricos críticos, empenhados com uma pedagogia crítica, em pensar o lugar da educação no enfrentamento dos temas sociais contemporâneos e assumir um lugar de agência no mundo. $O$ pano de fundo do autor, embora radicado nos Estados Unidos da América, não é muito diferente do que vivemos no Brasil. Inclusive sua referência remete sua esperança ao que acontece ou que aconteceu em Porto Alegre - RS no final do século XX, no Brasil, ou mesmo ao legado teórico de Paulo Freire.

Esta breve consideração nos possibilita pensar sobre a natureza das questões que levantamos acerca dos sentidos da educação na contemporaneidade. Um certo legado da teoria crítica, desdobrou-se em um legado da teoria educacional crítica, a qual, não de forma inocente e ingênua, busca construir um modo de agência em torno de uma pedagogia crítica no adentrar do século XXI. De outra parte, nos permite analisar as condições de possibilidade do discurso crítico, tento em vista certo avanço de perspectivas neoliberais e de empobrecimento da política. Aspecto que não corrobora a ideia de Brayner (1995) de que o discurso pedagógico acerca da possibilidade da transformação social possa necessariamente se converter em forma de politicismo.

A pergunta acerca das relações entre educação e sociedade, obviamente, demonstram de uma parte, certa aposta de que a educação tem um significado na constituição do mundo, e de outra que ela é constituída nas relações com o mundo social e histórico, como bem afirmou Cornelius Castoriadis (1992). O teórico crítico, percebendo-se como parte do que se movimenta, interroga, se há alguma forma de participar de outro modo na constituição do mundo ao invés de ser apenas por ele arrastado. Talvez aqui esteja um sentido forte do significado da teoria crítica em geral, ou mesmo do pensamento crítico, a de que o mundo esteja sempre em processo de constituição, e nunca se apresente de uma forma dada e acabada tal como sinalizou Karl Marx no século XIX.

Vale destacar que mesmo que Marx (2005) não tenha dado uma resposta satisfatória ou suficiente à questão da política, seu modo de interrogação da sociedade no interior do século XIX, possibilita entender parte do que depois ficou conhecido como uma forma de humanismo racionalista implicado com a denúncia de todas as formas de exploração, dominação e opressão (SÁNCHEZ VÁSQUEZ, 2002). Neste sentido, a dívida da teoria social crítica na atualidade, e mesmo da teoria educacional crítica, com o legado teórico de Karl Marx, é inegável, em medida que ele se interroga acerca de como se constitui o mundo social moderno (MILOVIC, 2004). A presença ou não do valor da teoria marxiana, ou mesmo daqueles que reescreveram e reatualizaram suas categorias e sentidos, fundindo este legado, com outras versões da 
filosofia, da antropologia e da sociologia moderna, ao longo do século XX, é testemunho, de que esta tradição teórica, em parte merece um questionamento radical, como também merece ter suas questões e propósitos reconhecidos. Nas palavras de Berman (2001), é possível compreender este diálogo entre a crítica de Arendt e a perspectiva de Marx sobre o mundo moderno, entendendo que:

Arendt, em $A$ condição humana, compreende algo que os críticos liberais de Marx em geral não percebem: 0 verdadeiro problema do pensamento de Marx não é um autoritarismo draconiano, mas o exato oposto disso, a falta de base para todo tipo de autoridade. "Marx previu corretamente, ainda que com um entusiasmo injustificado, o atrofiamento da esfera pública sob as condições do desenvolvimento desenfreado das forças produtiva da sociedade". [...] Arendt percebe claramente a extensão do individualismo que está por trás do comunismo de Marx e percebe também as dimensões niilistas a que esse individualismo pode conduzir. [...] Essa crítica a Marx levanta uma questão humana autêntica e urgente, mas Arendt, não chega mais perto de solucionar o problema do que chega Marx. [...] Ela tem razão quando diz que Marx nunca desenvolveu uma teoria da comunidade política e também quando diz que é um problema sério. Mas a questão é que, dado o ímpeto niilista do desenvolvimento pessoal e social moderno, não fica nenhum pouco claro que tipo de elos políticos os homens modernos podem criar. 0 problema que atinge o pensamento de Marx, portanto, vem a ser um problema que perpassa toda a estrutura da vida moderna em si (BERMAN, 2001, p.17).

Neste contexto, a pergunta de Apple (2017), se a educação pode mudar o mundo, em uma nova versão da teoria crítica, obviamente que segue atual, mas as formas e o como mudar o mundo, alteraram-se radicalmente após os acontecimentos do século XX e a crítica radical realizada por Arendt acerca do totalitarismo. ${ }^{1}$ Talvez seja importante destacar também um certo pessimismo alimentado pela teoria crítica em geral (produzida no século XX), ou mesmo pelo que veio depois dela, como forma de teoria pós-crítica, seja como forma de tentativa de sua demolição e desconstrução, seja como forma de sua reconstrução (HABERMAS, 1990). Em ambos os casos, o que emerge como resultado, seja dos acontecimentos sociais, que ocorrem no Brasil e no mundo, seja do ponto de vista dos teóricos e intelectuais, no início do século XXI, é um sentimento geral de impotência frente à fragilização da política e do poder de agência (SILVA, 2016). Vale assinalar, e assim o faz Russel Jacoby (2001), que o fim das utopias igualitaristas, que adveio após a crítica do totalitarismo na década de 50, e mesmo após o advento do pós-modernismo, com sua defesa do multiculturalismo, na década de 80 , ensejou um certo conformismo, do ponto de vista da política, que acabou por alimentar certa ideia de que a sociedade não poderia ser modificada.

Este testemunho, embora bastante radical, coincide com certo tipo de cultura política que alimenta o contemporâneo. Uma cultura marcada pela retomada dos ideais conservadores, associados com os ideais modernizantes. De uma parte, esta cultura vem embalada com uma crítica radical dos ideais iluministas e de todos os sentidos democráticos e republicanos neles embutidos e, de outra vem marcada pela busca da inovação e da participação mesmo que precarizada, nos novos movimentos mundializados do capital. Um paradoxo, que se alimenta de ideias pré-modernas, religiosas, para promover e intensificar o que há de mais forte e significativo no moderno - o lucro, ou melhor, a reprodução do capital, ou mesmo a religião do dinheiro e do poder. "Os liberais nos dizem: 'É preciso confiar no mercado'. Mas o que estes neoliberais dizem hoje foi refutado pelos próprios economistas acadêmicos nos anos 30" (CASTORIADIS, 2001, p. 35).

1 Claude Lefort (1990; 1991), embora concorde e parta da crítica de Arendt em relação à Marx, entende que a autora valoriza pouco a questão da democracia e das lutas sociais e libertárias em sua obra detendo-se mais nas tradições liberais e republicanas americanas. 
$\mathrm{Na}$ interpretação de Apple (2017, p.18), "[...] no status neoliberalista, escolha, competição, mercados, nos levarão à terra prometida de escolas eficientes e eficazes. $E$ tais escolas terão um papel fundamental na transformação do público em privado". Condição que significa que a educação em curso no contemporâneo está de certa forma implicada com a transformação social, mas isso não representa que ela pretenda beneficiar a maioria, nem que irá necessariamente ampliar o processo de democratização. No caso deste avanço dos poderes do mercado e da economia sobre a educação, a transformação parece ter ido para trás, e estamos vivendo um tempo de regresso. Nas palavras de Castoriadis (2001, p.38), "[...] hoje o que domina é a resignação", mesmo entre os liberais, e eles dizem: "talvez esteja ruim assim, mas o outro termo da alternativa é pior", ou mesmo: "se mexermos demais iremos em direção a um novo gulag". ${ }^{2}$

Neste sentido, mesmo que certa noção de política, de conhecimento e de conscientização possam ser assumidas ou ter sido assumidas de forma dogmática na educação escolar, as quais são denunciadas por Brayner (1995), cumpre ficarmos atentos ao fato de que o projeto educacional, de cunho emancipatório, tal como foi formulado por Kant (2013), e reconceptualizado por Paulo Freire (2000), por Cornelius Castoriadis (1992), e mesmo por Zygmunt Bauman (2009), considerando as críticas de Marx (2005) à modernidade, e as críticas em relação ao próprio Marx (CASTORIADIS, 2001), contêm a ideia de que uma sociedade para ser autônoma ou democrática precisa amparar-se na ideia de crítica, a qual pode ser promovida também pela educação, principalmente, no que tange aos critérios. ${ }^{3}$ Condição que nos movimenta para pensar um projeto de EF não apenas em perspectiva republicana, como, também, fundamentalmente, democrática. Projeto que parece exigir uma permanente capacidade instituinte dos sujeitos, em relação ao instituído, como asseverou Castoriadis (1982; 1992). Isto significa reconhecer o mérito das democracias representativas, mas caminhar para a construção de democracias participativas, ou mesmo sociedades autônomas.

\section{QUE SERIA UMA EDUCAÇÃO FíSICA CRÍTICA EM PERSPECTIVA DEMOCRÁTICA E REPUBLICANA?}

A história da Educação Física brasileira não depõe a favor de um vínculo entre as expectativas desta, no interior da escola, e os compromissos de uma educação republicana e democrática de orientação crítica. Distanciamento que torna explícito a dívida deste componente curricular com os regimes autoritários que se contrapuseram aos curtos períodos democráticos. Não é descabido, portanto que quando adentramos em uma experiência democrática mais prolongada, sua legitimidade seja posta em suspensão bem como sua própria base legal, objeto até então de decretos que dispensavam um esforço legitimador de caráter republicano.

Diante desta "ameaça" a sua presença no interior da escola, a Educação Física brasileira reagiu política e corporativamente para garantir este lugar agora sob novos argumentos. Não vamos nos prolongar aqui em torno deste "movimento renovador", em suas diversas nuances, mas enfatizar o fato de que a EF pleiteia fundamentalmente romper com sua tradição, que a circunscrevia apenas na condição de "atividade", para constituir-se em uma "disciplina".

2 "Eis o que há por trás deste esgotamento ideológico de nossa época, e creio que só sairemos dele pelo ressurgimento de uma potente crítica do sistema e um renascimento da atividade das pessoas, da sua participação na coisa comum" (CASTORIADIS, 2001, p.38).

3 "Os destinos da liberdade, da democracia que a torna possível - ao mesmo tempo que é possibilitada por ela - e da educação que produz a insatisfação com o nível de liberdade e democracia até aqui atingido são inextricavelmente ligados e não podem ser separados um do outro" (BAUMAN, 2009, p.23). 
Enfim, este movimento configura a EF como um campo curricular que precisa cumprir uma função educativa, tal como a que se espera do conjunto da escola, alicerçada em objetivos e conteúdos específicos que não dissolvem sua tarefa em generalidades e que seja capaz de sistematizar ao longo dos anos escolares, um conjunto de conhecimentos que permitam compreender, a partir de seus temas, o mundo que habitamos, bem como a dimensão humana que se liga às práticas corporais.

Na perspectiva formulada, ${ }^{4}$ a Educação Física é um componente curricular que deve responder pelo caráter republicano da instituição a que se vincula, no modo de tratar os conteúdos que Ihe dizem respeito. $O$ que implica em não limitar-se a reproduzir os sentidos/significados presentes nas diferentes manifestações da cultura corporal de movimento, procurando, ao tematizá-los, desnaturalizá-los, evidenciando a pluralidade de sentidos/significados que os sujeitos podem dar a eles. Pluralidade que só instituições com esse caráter pode preservar e que não são necessariamente compatíveis com os marcos de outros modos humanos de organizar a vida em sociedade.

A possibilidade de pensarmos nestes termos e assumir esta posição deve-se ao fato de hoje não termos que optar maniqueisticamente por um dos polos que se apresentavam como alternativa no início do século XX. A adesão incondicional ao status quo burguês ou assumir a bandeira de uma "ruptura revolucionária". Qualquer posição que não explicitamente estas eram "empurradas" para um desses extremos, sob a acusação, por um lado, de "fazer o jogo do sistema" ou, por outro, de "inocente útil".

Sabemos que esse modo de enfrentar os desafios sociais persistem na contemporaneidade e contam com uma realidade social que demanda proposições contundentes, as quais revestem-se de uma emergência que foram incompatível com a prudência da democracia e das instituições republicanas. No entanto, nesse momento, com as lições do século XX, também nossas ilusões com as saídas milagrosas parecem desgastadas.

Nesta perspectiva, assumimos que a principal característica das sociedades modernas que se pautam por um ideário republicano e democrático é sua fragilidade constitutiva. Não possuem elas nenhuma base metafísica de caráter epistemológico ou ontológico. Não há "ciência", "raça" ou "classe" que encarne o fundamento de sua existência. Obviamente convive com a disputa de poder que envolve interesses dos indivíduos, grupos e classes sociais, que a compõem. Porém, esses constroem sua legitimidade por, real, ou pretensamente, incorporar os "interesses da maioria", de onde provém sua legitimidade.

A partir desse ideário, a atuação do professor pode ser pautada a partir de diferentes dimensões e, de alguma forma, todas são atravessadas pelo balizamento ético-político sobre o que é necessário dar conta de um determinado projeto educativo. Entretanto, dado os limites do artigo e do estágio de desenvolvimento das ideias, destacamos três dimensões.

\subsection{A RELAÇÃO EDUCAÇÃO-POLÍTICA}

Quando presenciamos uma solenidade de formatura no Brasil escutamos do representante da reitoria algo como: "[...] em nome das leis da república eu os concedo o título de [...]" ou seja, naquele momento ele representa a república e é por ela e para ela, não para

4 Ver González; Fensterseifer (2009; 2010), Fensterseifer; González, (2011), Fensterseifer, González, Silva; Schwengber (2013). 
o governo vigente, que outorga licença de atuação profissional. Obviamente que esta licença tem por base as leis e pressupõe sua obediência e aperfeiçoamento.

Em uma república esta relação com as normas institucionais porém, não significam "obediência cega" e "subordinação incondicional", como antecipamos no parágrafo anterior, significa também contribuir para seu "aperfeiçoamento". É essa plasticidade que permite sempre atualizar nossas compreensões acerca do "bem comum" e capacitar-nos para sua efetivação.

A respeito disso a escola deve manter-se fiel à pluralidade compatível com o espírito democrático-republicano, tornando esclarecida a diversidade de posições que compõem nossa sociedade. Não deveríamos jamais esquecer que a liberdade acadêmica que usufruímos é uma prerrogativa das sociedades democrático-republicanas, e que tem na sua constituição a possibilidade de crítica constante a essa própria sociedade. Algo impensável em sociedades em que o Estado não é laico, ou onde há uma "ideologia oficial". No primeiro isso seria uma heresia, no segundo, desvio de conduta.

\subsection{A RELAÇÃO COM O CONHECIMENTO}

Podemos considerar que no sentido amplo da educação "todos aprendem com todos", que toda relação humana educa, porém se pensarmos na especificidade da educação escolar, devemos reconhecer que o conhecimento não está igualmente distribuído entre professores e alunos, professores e comunidade e entre professores de áreas distintas. Portanto a licença que possuímos da república é para dar conta de temas/conteúdos específicos, os quais foram objetos de nossa formação, não para "ensinar qualquer coisa" ou "desenvolver competências socioemocionais" desprovidas de qualquer conteúdo.

Sabemos da importância de que o profissional ao se apropriar de um saber especializado de caráter disciplinar não deveria significar menosprezo por aspectos gerais relativos ao mundo humano, social e histórico. Se esse saber é necessário não deriva daí que ele é suficiente, pois para participarmos, de um "discurso prático" (ação ético-política) seja no plano geral da sociedade, seja nos espaços de atuação profissional, necessita-se de formação que enriqueça nossa percepção do entorno no qual se situa nossa especialidade.

Assumir essa perspectiva, significa perceber a relação dos conhecimentos com o qual trabalhamos com o todo que compõe o mundo humano (social e histórico) e que 0 real é sempre mais rico que aquilo que se visualiza pela "janela disciplinar". Na perspectiva republicana crítica, isso se traduz no esforço do professor compreender e fazer compreender a seus alunos a dimensão histórico-cultural dos fenômenos com os quais a disciplina trata, para além de sua dimensão mais técnica. ${ }^{5}$

Por fim, ainda em relação ao trato com o conhecimento, cabe manter viva uma reflexão de caráter epistêmico que reconheça o caráter proposicional dos saberes que produzimos e ensinamos. Não cabe ao professor (ou cientista) colocar-se no lugar de oráculo anunciador de verdades acabadas. A desmistificação da ciência "[...] potencializa o papel do professor (que deixa de ser um simples repetidor), também potencializa o aluno, transformando a aula em um tempo-espaço de produção de saberes, no qual se validam, ou não, os significados embutidos nos conteúdos" (FENSTERSEIFER, 2009, p. 207-208).

5 Sobre as características dessas dimensões ver González e Fraga (2012) e González e Bracht (2012). 


\subsection{A RELAÇÃO ENTRE EDUCAÇÃO E SOCIEDADE}

Mas, o que isto significa para nossa ideia de pensar o vínculo entre sociedade, educação, democracia e mudança social? Ou mesmo de pensar se a EF pode ser crítica e sob quais condições? De certo modo, a educação, desde o projeto da modernidade iluminista, foi concebida como uma forma de mudar ou de conservar o mundo social por intermédio do conceito, do conhecimento ou da ideia. O espírito crítico parece nos alimentar a ideia de que nada é natural ou mesmo cai dos céus ou brota espontaneamente da terra, mas que está permanentemente sendo feito e refeito e em disputa no âmbito das relações sociais, culturais e políticas. Os acontecimentos cotidianos teimam em assinalar que tudo já está ou deve estar vinculado com o crescimento da economia (com a modernização), e de que todos precisam aceitar o destino inexorável que está sendo projetado pela atual globalização.

O discurso do cotidiano não permite questões, dúvidas radicais, que ajudem a pensar e compreender os mecanismos que estruturam a vida social, bem como o caráter histórico das relações sociais e produtivas que circunstanciam a vida política. Neste sentido, ele é portador de um cegueira, a qual objetiva obliterar o pensamento que busca compreender os poderes e imaginários que organizam a vida social e que se manifestam no âmbito da educação escolar.

Sob este aspecto, as tradições críticas e pós-críticas permitem à EF, tanto na escola quanto na universidade, compreender o caráter inconcluso ou mesmo deformado das apostas das sociedades democráticas e republicanas, permitindo ou desafiando uma crítica permanente das ideologias e seus modos sucintos de produzir efeitos de dominação sobre os corpos, culturas e sociedades. Neste sentido, ela não muda a sociedade de forma direta, mas cria as condições sociais e culturais (formativas) para que os sujeitos percebam o caráter inconcluso e contraditório do mundo social e histórico, para que assim possam nele atuar de forma a problematizar, julgar e intervir rumo a outros horizontes de liberdade, igualdade e justiça social.

\section{CONSIDERAÇÕES FINAIS}

Vimos ao longo do estudo, que a negação de certo discurso crítico de cunho vanguardista na política, não significa, de forma alguma, a negação e o valor das teorias e discurso críticos em educação. Trata-se, outrossim, de manter uma autocrítica em relação às formas de apropriação de certas formas de crítica, de modo a controlar seus excessos e riscos, para retomá-lo, em um outro sentido de contraponto, como um aspecto relevante e mesmo constitutivo da agenda da modernidade, ou ainda da emancipação humana. Obviamente, que esta nova forma de crítica na EF, não se alimenta de muitas das ilusões da modernidade, tal como a de: a) construir um paraíso social na Terra; b) imaginar-se sem arestas, lacunas e erros; c) ser independente das dimensões subjetivas, intersubjetivas, e mesmo sociais e históricas envoltas nas questões democráticas e republicanas.

Isto nos permitiu ao longo do estudo evidenciar que as tradições críticas, mantêm a discussão sobre a questão social e democrática, em torno da busca pela igualdade social, no âmbito do capitalismo, enquanto as tradições republicanas e liberais, discutem a questão da centralidade da política, das instituições, das normatividades jurídicas, defendendo a liberdade do debate, ou mesmo configurando o lugar da esfera pública, como palco resguardado por uma constituição, que nos ajuda a pensar, discutir e deliberar sobre os rumos da mudança social. 
Imaginamos, neste sentido, que a crítica social, tal como a produzida por Paulo Freire em sua pedagogia, dentre outros, continua tendo seu valor na contemporaneidade, principalmente por evidenciar as contradições e déficits do projeto moderno e seu discurso proclamado em torno da emancipação, ou mesmo da presença das esferas públicas, e das subjetividades envolvidas na construção de sociedades democráticas no século XXI. Aspecto que não nos retira do compromisso de ler criticamente Paulo Freire e controlar certo politicismo que pode advir de sua obra.

Com este tipo de análise ambivalente, contraditória e complexa, consideramos e assumimos os valores e aportes que: a) emergem do enfoque hermenêutico, o qual amparado em Arendt (2013), sinaliza para o valor da educação como uma prática social relacionada com o conhecimento e a conservação das memórias e tradições na EF, distinguindo educação e política; b) brotam do enfoque crítico social, o qual amparado em Marx, e na reconstrução das possibilidades e formas de teoria crítica, tal como o fizeram Adorno (2003), Horkheimer (1980), Habermas (1990; 2000), Freire (2000), Castoriadis (2001) e Bauman (2009), dentre outros, possibilitam apontar para o valor da educação e da EF, como uma prática social relacionada não somente com a conservação das tradições do passado, como também com o questionamento radical das ideologias que constituem o mundo presente, o que permite pensar na mudança social rumo a formas mais radicais de democracia na contemporaneidade.

Neste sentido, consideramos que a discussão sobre os vínculos entre educação, república e democracia no âmbito da EF, pode se valer, tanto dos aportes das tradições hermenêuticas, como das tradições crítico-dialéticas e pós-estruturalistas. Movimento que tem sido levado adiante por àqueles que, nos rastros de Zygmunt Bauman (2009; 2010), por exemplo, articulam tanto a crítica de Arendt, e da hermenêutica em geral, quanto de Adorno, e da teoria crítica em geral, quanto de Foucault, e do enfoque pós-estruturalista em geral. Condição que permite uma hermenêutica plural em torno do significado e alcance das teorias críticas no âmbito das lutas por sociedades democráticas e republicanas. A educação e a EF escolar, neste sentido, parecem ser responsáveis, tanto por conservar um bem comum, um conhecimento poderoso (YOUNG, 2007), quanto por permitir uma crítica social (APPLE, 2017), que anos ajude a compreender o presente, e redesenhar nosso futuro social.

\section{REFERÊNCIAS}

ADORNO, Theodor. W. Educação e Emancipação. Tradução de Wolfgang Leo Maar. 3. ed. Rio de Janeiro: Paz e Terra, 2003.

APPLE, Michael W. A educação pode mudar a sociedade? Tradução de Lilia Loman. Petrópolis, RJ: Vozes, 2017.

ARENDT, Hannah. Entre o passado e o futuro. Tradução de Mauro W. Barbosa. 7. ed. São Paulo: Perspectiva, 2013.

BAUMAN, Zygmunt. Vida líquida. Tradução de Carlos Alberto Medeiros. 2. ed. Rio de Janeiro: Jorge Zahar, 2009. 
BAUMAN, Zygmunt. Legisladores e intérpretes: sobre modernidade, pós-modernidade e intelectuais. Tradução de Renato Aguiar. Rio de Janeiro: Jorge Zahar, 2010.

BERMAN, Marshall. Aventuras no marxismo. Tradução de Sonia Moreira. São Paulo: Companhia das Letras, 2001.

BRAYNER, Flávio H. Ensaios de crítica pedagógica. Campinas, SP: Autores Associados, 1995.

CASTORIADIS, Cornelius. A instituição imaginária da sociedade. Tradução de Guy Reynaud. Rio de Janeiro: Paz e Terra, 1982.

CASTORIADIS, Cornelius. 0 mundo fragmentado: as encruzilhadas do labirinto 3. Tradução de Rosa Maria Boaventura. Rio de Janeiro: Paz e Terra, 1992.

CASTORIADIS, Cornelius. Pos-scriptum sobre a insignificância: entrevista a Daniel Mermet. Tradução de Salma Tannus Muchail e Maria Lucia Rodrigues. São Paulo: Veras, 2001.

FENSTERSEIFER, Paulo Evaldo. Epistemologia e prática pedagógica. Revista Brasileira de Ciências do Esporte, v.30, n.3, p.203-214, 2009.

FENSTERSEIFER, Paulo Evaldo; GONZÁLEZ, Fernando Jaime; SILVA, Sidinei Pithan da; SCHWENGBER, Maria Simone Vione. Educação Física nas avaliações em larga escala brasileira: balanço e desafios. In: BRASIL. Avaliações da Educação Básica em debate: ensino e matrizes curriculares de referência das avaliações em larga escala. Brasília: Instituto Nacional de Estudos e Pesquisas Educacionais Anísio Teixeira, 2013. p. 357- 386.

FENSTERSEIFER, Paulo Evaldo; GONZÁLEZ, Fernando Jaime. La educación física como disciplina curricular en una escuela republicana: notas para pensar la formación del profesorado. Ágora para la Educación Física y el Deporte, n. 13, v. 3, p. 299-320, sept./dec. 2011. Disponível em: https://www5.uva.es/agora/revista/13 3/agora13 3d fensterseifer et al. Acesso em: 20 jul. 2019.

FREIRE, Paulo. Pedagogia da esperança: um reencontro com a Pedagogia do Oprimido. 7. ed. Rio de Janeiro: Paz e Terra, 2000.

GONZÁLEZ, Fernando Jaime; FENSTERSEIFER, Paulo Evaldo. Entre o "não mais" e o "ainda não": pensando saídas para o não lugar da EF escolar II. Cadernos de Formação RBCE, v.1, n.1, p. 9-24, set. 2009.

GONZÁLEZ, Fernando Jaime; FENSTERSEIFER, Paulo Evaldo. Entre o "não mais" e o "ainda não": pensando saídas para o não lugar da EF escolar II. Cadernos de Formação RBCE, v.1, n.2, p. 10-21, mar. 2010.

GONZÁLEZ, Fernando Jaime; BRACHT, Valter. Metodologia do ensino dos esportes coletivos. Vitória: UFES, Núcleo de Educação Aberta e a Distância, 2012.

GONZÁLEZ, Fernando Jaime; FRAGA, Alex Branco. Afazeres da Educação Física na Escola: planejar, ensinar, partilhar. Erechim: Edelbra, 2012.

HABERMAS, Jürgen. Para a reconstrução do materialismo histórico. 2.ed. São Paulo: Brasiliense, 1990.

HABERMAS, Jürgen. 0 discurso filosófico da modernidade: doze lições. Tradução de Luiz Sérgio Repa e Rodnei Nascimento. São Paulo: Martins Fontes, 2000. 
HORKHEIMER, Max. Teoria tradicional e teoria crítica. Traduções de José Lino Grünnewald et al. In: BENJAMIN, W. et al. Textos Escolhidos. São Paulo: Abril Cultural, 1980. P. 245-294.

KANT, Immanuel. Textos Seletos. Tradução do original alemão por Raimundo Vier e os demais textos por Floriano de Sousa Fernandes. 9. ed. Petrópolis, RJ: Vozes, 2013.

JACOBY, Russell. O fim da utopia: política e cultura na era da apatia. Tradução de Clóvis Marques. Rio de Janeiro: Record, 2001.

LEFORT, Claude. As formas da história: ensaios de antropologia política. Tradução de Luiz Roberto Salinas Fortes e Marilena Chaui. 2. ed. São Paulo: Brasiliense, 1990.

LEFORT, Claude. Pensando o político: ensaios sobre democracia, revolução e liberdade. Tradução de Eliana M. Souza. Rio de Janeiro, Paz e Terra, 1991.

MARX, Karl. Crítica da filosofia do direito de Hegel. Tradução de Rubens Enderle e Leonardo de Deus. São Paulo: Boitempo, 2005.

MASSCHELEIN, Jan; SIMONS, Maarten. Em defesa da escola: uma questão pública. Tradução de Cristina Antunes. 2. ed. Belo Horizonte: Autêntica, 2017. (Coleção Educação: Experiência e Sentido).

MILOVIC, Miroslav. Comunidade da diferença. Rio de Janeiro: Relume Dumará; ljuí: Editora da Unijuí, 2004.

SANCHEZ VÁSQUEZ, Adolfo. Filosofia e circunstâncias. Tradução de Luiz Cavalcanti de M. Guerra. Rio de Janeiro: Civilização Brasileira, 2002.

SILVA, Sidinei Pithan da. Pós-Modernidade, Capitalismo e Educação: a universidade na crise do projeto social moderno. Curitiba: Appris, 2016.

TODOROV, Tzvetan. 0 espírito das luzes. Tradução de Mônica Cristina Corrêa. São Paulo: Barcarolla, 2008.

YOUNG, Michael. Para que servem as escolas? Educação e Sociedade, v. 28, n. 101, p. 12871302, set./dez. 2007. Disponível em: http://www.scielo.br/pdf/es/v28n101/a0228101.pdf. Acesso em: 13 jun. 2019. 